\title{
Atorvastatin improves tubular status in non-diabetic patients with chronic kidney disease - placebo controlled, randomized, cross-over study
}

\author{
Marcin Renke ${ }^{\bowtie}$, Leszek Tylicki ${ }^{1}$, Przemysław Rutkowski ${ }^{1}$, Alexander Neuwelt ${ }^{2}$, Wojciech \\ Larczyński ${ }^{1}$, Marcin Ziętkiewicz ${ }^{3}$, Ewa Aleksandrowicz ${ }^{4}$, Wiesława Łysiak-Szydłowska ${ }^{4}$ and \\ Bolesław Rutkowski ${ }^{1}$
}

'Department of Nephrology, Transplantology and Internal Medicine, Medical University of Gdansk, Poland; 2Blood Brain Barrier and NeuroOncology Program, Oregon Health \& Science University, Portland, Oregon, USA; ${ }^{3}$ Department of Internal Medicine, Connective Tissue Diseases and Geriatrics, and ${ }^{4}$ Department of Clinical Nutrition and Laboratory Diagnostics, Medical University of Gdansk, Poland

\begin{abstract}
Background. There is evidence that dyslipidemia is associated with chronic kidney disease (CKD) and it has been implicated in the progression of renal damage. Optimal management of dyslipidemia should therefore lead to renal benefits. A number of experimental models demonstrate a beneficial effect of statins in ameliorating renal damage. However, the exact mechanism by which statins protect against renal damage remains unclear. Methods. In a placebo-controlled, randomized, cross-over study we evaluated the influence of atorvastatin (ATO) $40 \mathrm{mg} /$ day added to the renin-angiotensinaldosterone systeme (RAAS) blockade on proteinuria and surrogate biomarkers of tubular damage or injury in 14 non-diabetic patients with proteinuria $(0.4-1.8 \mathrm{~g}$ per $24 \mathrm{~h}$ ) with normal or declined kidney function (eGFR 55-153 $\mathrm{ml} / \mathrm{min}$ ). In the eight-week run-in period, therapy using angiotensin converting enzyme inhibitors (ACEI) and/or angiotensin II subtype 1 receptor antagonists (ARB) was adjusted to achieve a blood pressure below $130 / 80 \mathrm{~mm} \mathrm{Hg}$. Next, patients were randomly assigned to one of two treatment sequences: ATO/washout/placebo or placebo/washout/ATO. Clinical evaluation and laboratory tests were performed at the randomization point and after each period of the study. The primary end point of this study was a change in proteinuria measured as 24-h urine protein excretion (DPE). Secondary end points included urine $N$-acetyl- $\beta$-D-glucosaminidase (NAG) and a1-microglobulin (a1m) excretion. Results. The ATO therapy significantly reduced urine excretion of $a_{1} m(P=0.033)$ and NAG $(P=0.038)$ as compared to placebo. There were no differences in proteinuria, blood pressure, eGFR and serum creatinine between the ATO and placebo groups. Conclusion. Atorvastatin treatment is safe and improves biomarkers of tubular damage or injury in non-diabetic patients with CKD.
\end{abstract}

Keywords: Atorvastatin, kidney, chronic kidney disease, proteinuria, tubular injury

Received: 21 May, 2010; revised: 16 October, 2010; accepted: 06 November, 2010; available on-line: 16 November, 2010

\section{INTRODUCTION}

Despite recent progress, there is still no optimal therapy that stops progression of renal disease. Therefore, it is necessary to search for alternative therapeu- tic strategies which can further improve renal outcome (Renke et al., 2010). There is evidence that dyslipidemia is associated with chronic kidney disease (CKD) (Guijarro \& Keane, 1993; Samuelsson et al., 1997). Experimental studies have established that lipids are damaging to the kidney (Keane et al., 1988; Rutkowski et al., 2003). The administration of various statins has been reported to exhibit beneficial effects in a number of experimental models of chronic kidney diseases suggesting that lipids may represent important therapeutic targets to halt or attenuate renal injury (Tylicki et al., 2003). The benefits of statins can be explained not only by their lipid-lowering potential but also by non-lipid related mechanisms, the so called "pleiotropic effects". Several studies have evaluated the effects of statins on the progression of $\mathrm{CKD}$ in human subjects but the results are controversial (Chan et al., 1992; Fuiano et al., 1996; Bianchi et al., 2003; Strippoli et al., 2008; Banach et al., 2009). Considering the prognostic impact of proteinuria reduction on long-term renal outcome, in the present study we evaluated the effects of addition of atorvastatin (ATO), a 3-hydroxy-3-methyglutaryl coenzyme A (HMG-CoA) reductase inhibitor, to background nephroprotective therapy consisting of angiotensin converting enzyme inhibitors (ACEI) and/or angiotensin II subtype 1 receptor antagonists (ARB). ATO, in contrast to many other statins, does not require dosage modification at any level of renal function (K/DOQI 2003). The patients were then evaluated for proteinuria, inflammation, renal function, and surrogate biomarkers of tubular injury. The primary end point of this study was a change in proteinuria measured as 24-h urine protein excretion (DPE), in measurements available for each patient. Secondary end points included urine $N$-acetyl- $\beta$-D-glucosaminidase (NAG) and $\alpha_{1}$ microglobulin $(\alpha 1 \mathrm{~m})$ excretion.

\section{e-mail: mrenke@gumed.edu.pl}

Abbreviations: a1m, a -microglobulin; ACEI, angiotensin converting enzyme inhibitors; ALAT, alanine aminotransferase; ARB, angiotensin II subtype 1 receptor antagonists; ASAT, aspartate aminotransferase; ATO, atorvastatin; BMI, body mass index; BP, blood pressure; $C K$, creatine phosphokinase; CKD, chronic kidney disease; CVD, cardiovascular diseases; DPE, 24-h urinary protein excretion; eGFR, estimated glomerular filtration rate; hsCRP, high sensitive Creactive protein; NAG, $N$-acetyl- $\beta$-D-glucosaminidase; RAAS-rennin, angiotensin-aldosterone systeme 


\section{METHODS}

Patients were selected from a cohort that attended our renal outpatients' department. The inclusion criteria were as follows: age 18-65 years, chronic non-diabetic proteinuric nephropathy without dyslipidemia, normal or slightly impaired stable renal function expressed as estimated glomerular filtration rate (eGFR) above $45 \mathrm{ml} / \mathrm{min}$, stable proteinuria above $300 \mathrm{mg} / 24 \mathrm{~h}$, and no steroids or other immunosuppressive treatment for a minimum of six months before the study. Stable renal function and proteinuria were defined as a variability of serum creatinine and proteinuria less than $25 \%$ during six months before the start of the study. Patients with total cholesterol less than $200 \mathrm{mg} / \mathrm{dl}$, low-density lipoprotein (LDL) cholesterol $<130 \mathrm{mg} / \mathrm{dl}$, and triglycerides < $150 \mathrm{mg} /$ dl were included. Exclusion criteria were as follows: nephritic syndrome, diabetes mellitus, cardiovascular disease (CVD), potassium serum level $>5.1 \mathrm{mmol} / \mathrm{l}$, history of malignancy including leukemia and lymphoma, fertile women who were not taking oral contraceptives, pregnant or lactating women, patients with active liver disease, i.e., aspartate aminotransferase (ASAT) or alanine aminotransferase (ALAT) values more than three times the upper reference values, and known or suspected contraindications to the study medications, including a history of adverse reactions to statins, ACEI or ARB.

General protocol. The study was a prospective, placebo-controlled, randomized, two-period cross-over trial in which the renal effects of adding ATO (Sortis; Parke-Davis, Pfizer Polska) to background nephroprotective therapy with ACEI and/or ARB (Xartan; Adamed Polska) were evaluated. At the beginning, subjects entered an eight week run-in period during which the background nephroprotective therapy using pharmacological blockade of RAAS was adjusted to give a target blood pressure (BP) below 130/80 $\mathrm{mm} \mathrm{Hg}$ (Table 1). At the end of the run-in period, patients were randomly assigned to one of two treatment sequences: twelve-week ATO (40 mg/day)/12week washout — background therapy/12-week placebo (sequence 1) or 12-week placebo/12-week washout - background therapy/12-week ATO (40 mg/day) (sequence 2) (Fig. 1). Allocation was performed by a person that was independent of the research team according to a computer generated randomized list. The patients received $40 \mathrm{mg}$ of ATO as tablets (Sortis 40, Pfizer) once a day. The target BP during the whole study was an office visit BP of $130 / 80 \mathrm{~mm} \mathrm{Hg}$ or less. The dosages of ACEI, ARB and diuretics, once established in the run-in period, were left unchanged throughout the study and in the washout period. At the randomization point and after the end of each treatment periods, office trough BP, serum creatinine, potassium, proteinuria measured as $24-\mathrm{h}$ urine protein excretion (DPE), sodium excretion ( $\mathrm{Na}$ ex), urea excretion, and surrogate markers of tubular injury (urine excretion of $N$-acetyl- $\beta$-D-glucosaminidase (NAG), $\alpha-{ }_{1}$-microglobulin $(\alpha 1 \mathrm{~m})$ ) were determined. The study was approved by the local ethical committee (NKE$\mathrm{BN} / 749 / 2003)$ and all the patients gave informed consent. The study was registered at www.clinicaltrials. gov and received a positive opinion (NCT00572312).

Procedures and laboratory analyses. The office trough BP was measured with Speidel+Keller sphyngomanometer in a sitting position after $10 \mathrm{~min}$ of rest and expressed as a mean value of two consecutive measurements taken $2 \mathrm{~min}$ apart. DPE, $\mathrm{Na}$ ex and urea excretion were evaluated on the basis of 24-h urine collection. All patients were equipped with a scaled container and were strictly informed how to collect 24-h urine. They collected two 24-h urines of those the mean value of DPE was calculated for data evaluation. Patients were asked not to perform heavy physical activity on the urine collection days and were recommended not to change their usual daily protein and sodium intake during the study period. The excretion of urea was used to calculate the protein intake according to Maroni equation: protein intake normalized to weight $(\mathrm{g} / \mathrm{kg}$ per day $)=6.25 \times([$ urea$\mathrm{N}$-excretion urine $24 \mathrm{~h}(\mathrm{~g} / \mathrm{day})]+[0.0031 \times$ body weight $(\mathrm{kg})]) /$ body weight (kg) (Maroni et al., 1985). eGFR was calculated according to Cockcroft-Gault formula (Cockcroft \& Gault, 1976). NAG and $\alpha 1 \mathrm{~m}$ were analyzed in the second morning spot urine sample. NAG was determined by the spectrophotometric method according to Maruhn (1976). Incubation medium contained in a final volume of $0.4 \mathrm{ml}, 5 \mathrm{nmol} / 1$ $P$-nitrophenyl-2-acetamido- $\beta$-D-glucopyranoside as a substrate in $50 \mathrm{mmol} / \mathrm{l}$ citrate buffer ( $\mathrm{pH} 4.14)$. The reaction was started by the addition of $0.2 \mathrm{ml}$ of undialysed urine, carried out for $15 \mathrm{~min}$. at $37^{\circ} \mathrm{C}$, and then terminated with $1 \mathrm{ml}$ of glycine buffer, pH 10.5. Absorbance was measured at $405 \mathrm{~nm}$ against a sample terminated at time zero. The calculation of the NAG level was made from the molar absorbance coefficient of the product of the reaction, $P$-nitrophenol, equal to 18.5 $\mathrm{cm}^{2} / \mu \mathrm{mol}$. From preliminary experiments it was clear that the dialysis of urine did not affect NAG level in urine. Immunoturbidimetric test (Tina-quant $\alpha_{1}$-microglobulin, Roche, Basel, Switzerland) was used for quantification of

Figure 1. 
Table 1. Patient characteristics at baseline

\begin{tabular}{ll}
\hline Parameter & \\
\hline Gender: female/male $(\mathrm{n})$ & $7 / 7$ \\
Mean age (years) & $34.2 \pm 6.94$ \\
Mean systolic blood pressure $(\mathrm{mm} \mathrm{Hg})$ & $111.5 \pm 7.8$ \\
Mean diastolic blood pressure $(\mathrm{mm} \mathrm{Hg})$ & $71.2(66.4-75.7)$ \\
Urinary protein excretion (g/24 h) & $0.85(0.35-1.8)$ \\
Serum creatinine (mg/dl) & $1.05 \pm 0.27$ \\
eGFR (ml/min) & $104.7 \pm 33.3$ \\
Total cholesterol (mg/dl) & $191.9 \pm 21$ \\
hsCRP (mg/l) & $0.91(0.33-2.22)$ \\
BMI (kg/m²) & $25.97(23.3-29.3)$ \\
Histopatological diagnosis: $(\mathrm{n})$ & 8 \\
Mesangial glomerulonephritis & 1 \\
Mesangiocapillary glomerulonephritis & 3 \\
Membranous glomerulonephritis & 1 \\
IgA nephropathy & 3 \\
Unknown non-diabetic proteinuric chronic kidney diseases & 6 \\
Background hypotensive therapy: (n) & \\
ACEl and ARB & 10 \\
ACEl & 3 \\
ARB & 1 \\
\hline
\end{tabular}

Note: To convert serum creatinine in $\mathrm{mg} / \mathrm{dl}$ to $\mu \mathrm{mol} / \mathrm{l}$, multiply by 88.4 ; eGFR in $\mathrm{ml} / \mathrm{min} / 1.73 \mathrm{~m}^{2}$ to $\mathrm{ml} / \mathrm{s} / 1.73 \mathrm{~m}^{2}$, multiply by 0.01667 ; Abbreviations: BMl, Body mass index; hsCRP, high sensitive C-reactive protein; eGFR, estimated glomerular filtration rate

$\alpha 1 \mathrm{~m}$ in urine. The detection limit of the method was $2 \mathrm{mg} / \mathrm{l}$. Urinary NAG and $\alpha 1 \mathrm{~m}$ were reported per $\mathrm{mg}$ or $g$ of urine creatinine to correct for the variation in urine concentration. We measured high sensitive C-reactive protein (hsCRP) with a commercial ELISA Kit (DRG, EIA-3954) and reported it in $\mathrm{mg} / \mathrm{l}$. Total cholesterol, LDL cholesterol, HDL cholesterol, serum triglyceride, ASAT, ALAT, creatine phosphokinase (CK), potassium, sodium, urea, protein and creatinine levels were measured in fresh blood samples drawn after fasting overnight for at least $12 \mathrm{~h}$. These parameters were measured by standard laboratory techniques. Body mass index (BMI) was calculated asmass (kilograms) divided by height (meters) squared. Adverse effects were recorded at each visit in response to questionnaires or as observed by the investigators.
Statistics. The primary end point of this study was a change in DPE in measurements available for each patient. A sample size of 12 patients adequately allowed a power of $80 \%$ to detect a difference in variables equal to within patient standard deviation, that is a standardized effect size of 1.0 at a significance level of 0.05 (two-tailed). Secondary end points included urine NAG and $\alpha 1 \mathrm{~m}$ excretion. Normality and homogeneity of the variances were verified by means of the Shapiro-Wilk test and Levene test, respectively. Because of their skewed distribution, diastolic BP, DPE, NAG excretion, hsCRP, serum creatinine and daily protein intake were logarithmically transformed before statistical analysis and expressed as geometric means and 95\% confidence intervals. Other results are presented as means \pm S.E.M. Differences in variable changes between treatment with ATO and placebo were assessed using Student's t-test (Table 2). Differences in variables measured more than twice (Table 3) were assessed using ANOVA. $P$ values less than 0.05 (2-tailed) were considered statistically significant. Data were evaluated using Statistica (version 7.1; StatSoft Inc., Tulsa, $\mathrm{OK})$ software package.

\section{RESULTS}

Of the 14 patients who entered the study, 12 (86\%) completed the protocol. Two of them were dropped out because of withdrawal of informed consent. This decision was not due a side effect of therapy. Clinical characteristics of patients are listed in Table 1.

\section{Twenty-four-hour urine protein excretion (DPE)}

There was no significant change in DPE after ATO as compared to placebo (Table 2).

Table 2. Changes of parameters after ATO and placebo

\begin{tabular}{lccc}
\hline & Baseline - ATO $\Delta$ & Baseline - Placebo $\Delta$ & $P$ \\
\hline DPE (g/24 h) & $-0.23 \pm 0.08$ & $-0.001 \pm 0.13$ & 0.98 \\
a1m excretion (mg/g creat.) & $-8.18 \pm 3.39$ & $-0.17 \pm 0.68$ & 0.033 \\
NAG excretion (IU/creatinine) & $-0.92 \pm 0.29$ & $-0.16 \pm 0.18$ & 0.038 \\
Total cholesterol (mg/dl) & $-68.88 \pm 7.52$ & $-0.11 \pm 8.44$ & 0.001 \\
LDL-C (mg/dl) & $-49.0 \pm 4.25$ & $-3.22 \pm 6.02$ & 0.001 \\
HDL-C (mg/dl) & $-5.88 \pm 2.85$ & $-1.22 \pm 1.21$ & 0.14 \\
Triglycerides (mg/dl) & $-21.88 \pm 14.2$ & $15.4 \pm 16.16$ & 0.12 \\
\hline
\end{tabular}

Note: To convert total cholesterol, low-density lipoprotein cholesterol (LDL-C), high-density lipoprotein cholesterol (HDL-C) in $\mathrm{mg} / \mathrm{dl}$ to $\mathrm{mmol} / \mathrm{l} \mathrm{mul-}$ tiply by 0.02586 . To convert triglycerides in $\mathrm{mg} / \mathrm{dl}$ to $\mathrm{mmol} / \mathrm{l}$ multiply by 0.01129 . Abbreviations: DPE, urinary protein excretion; a $\mathrm{m}, \mathrm{a}_{1}$-microglobulin; NAG, $N$-acetyl- $\beta$-D-glucosaminidase 
Table 3. Changes of parameters during the study

\begin{tabular}{|c|c|c|c|c|}
\hline Parameter & Randomization point & After ATO & After Placebo & $P$ \\
\hline Sodium urine excretion ( $\mathrm{mmol} / 24 \mathrm{~h}$ ) & $223.9 \pm 28.8$ & $208.8 \pm 27.3$ & $215.1 \pm 28.4$ & 0.68 \\
\hline Daily protein intake (g/24 h) & $1.1(0.93-1.14)$ & $1.0(0.94-1.12)$ & $1.12(0.83-1.39)$ & 0.64 \\
\hline Serum creatinine (mg/dl) & $1.05 \pm 0.1$ & $1.07 \pm 0.1$ & $1.12 \pm 0.1$ & 0.08 \\
\hline hsCRP (mg/l) & $0.91(0.3-2.21)$ & $0.47(0.29-0.77)$ & $0.77(0.4-1.49)$ & 0.47 \\
\hline ALAT (IU/I) & $22.3(18.6-27.8)$ & $29.6(19.3-48.2)$ & $22.2(17.1-30.5)$ & 0.049 \\
\hline ASAT (IU/I) & $20.4(17.8-23.8)$ & $25.2(16.8-38.6)$ & $19.9(17.4-23.0)$ & 0.089 \\
\hline Creatine phosphokinase (IU/I) & $97(18-252)$ & $111.8(85.7-153)$ & $93.5(18-240.6)$ & 0.14 \\
\hline Systolic blood pressure (mmHg) & $111.5 \pm 2.5$ & $114.4 \pm 2.12$ & $115.0 \pm 1.97$ & 0.27 \\
\hline Diastolic blood pressure $(\mathrm{mmHg})$ & $71.2(66.4-76.6)$ & $72.1(68.8-75.6)$ & $69.5(67.5-71.5)$ & 0.67 \\
\hline
\end{tabular}

Note: To convert serum creatinine in $\mathrm{mg} / \mathrm{dl}$ to $\mu \mathrm{mol} / \mathrm{l}$, multiply by 88.4. Abbreviations: hsCRP, high sensitive C-reactive protein; ASAT, aspartate aminotransferase; ALAT, alanine aminotransferase

\section{Urinary NAG and a1m excretion}

Urinary NAG $(P=0.038)$ and $\alpha 1 \mathrm{~m}$ excretion $(P=0.033)$ decreased significantly after adding of ATO as compared to placebo (Table 2).

\section{Serum lipid levels}

Total cholesterol $(P=0.001)$ and LDL cholesterol $(P=0.001)$ decreased significantly after ATO as compared to placebo. There were no significant changes in triglyceride and HDL cholesterol during the study (Table 2).

\section{Blood pressure, renal function, hsCRP, sodium and protein intake}

The control of BP was adequate in all study periods; all patients reached the target office trough BP below 130/80 $\mathrm{mm} \mathrm{Hg}$. There were no differences in office trough systolic and diastolic BP between the treatment periods. Renal function assessed by means of serum creatinine and eGFR remained stable throughout the study. hsCRP levels had a tendency to decrease in ATO treatment but it was not statistically significant $(P=0.47)$. There were no differences in sodium and protein intake between treatment periods (Table 3).

\section{Safety}

ATO therapy was well tolerated by all patients. Adverse effects were not reported. ASAT and CK were unchanged during the study period. ALAT statistically increased after ATO $(P=0.049)$ but it was still in the normal range.

\section{DISCUSSION}

To the best of our knowledge, the present study was the first to evaluate the influence of atorvastatin, an HMG-CoA reductase inhibitor, on the markers of renal outcome in proteinuric CKD patients without dyslipidemia and CVD. We analysed the effects of ATO (40 $\mathrm{mg} /$ day) on proteinuria, the fundamental marker of glomerular injury and impaired glomerular permselectivity. Proteinuria is also a marker of long-term renal outcome. In the present study, the administration of ATO provided no change in proteinuria level $(P=0.98)$ in non-diabetic CKD patients. Only a few randomized controlled trials directly addressing the effect of statins on renal function and proteinuria have been reported. Most of those studies were of small size or short duration, used a variety of statins, and many did not include a placebo arm. Some of them suggest that statins reduce proteinuria and the rate of decline of GFR (Bianchi et al., 2003; Tonelli, 2006). These positive effects have been summarized in published meta-analyses (Fried et al., 2001; Sandhu et al., 2006; Strippoli et al., 2008). Interestingly, there are also studies suggesting that statins, particularly at high doses, may increase proteinuria (Deslypere et al., 1990; Verhulst et al., 2004). Finally, the National Lipid Association Statin Safety Task Force recently reported that statin-induced proteinuria is not associated with renal impairment or renal failure (McKenney et al., 2006).

Considering that tubular epithelial cell injury may initiate the fibrosis process in kidneys and the fact that the extent of tubulointerstitial damage is a crucial predictor of renal outcome, tubular cells have become a renal site of particular interest. To evaluate tubulointerstitial effects of our interventions, the tubular involvement markers NAG and $\alpha 1 \mathrm{~m}$ were analysed (Bazzi et al., 2002).

An increased excretion of NAG is thought to be a specific marker of tubular injury in many renal pathologies including non-diabetic CKD (Bazzi et al., 2002). Increased urinary excretion of $\alpha 1 \mathrm{~m}$, a low-weight protein physiologically filtered and reabsorbed by tubular cells, might indicate a reduced capacity of its reabsorption by such cells and it might be a marker of established tubular damage, with greater urinary concentrations pointing to greater severity of damage (Holdt-Lehmann et al., 2000). Our results show that treatment with ATO reduces markers of tubular injury. Similar results (although in experimental models) were described by Tsujihata and co-workers (2008). That group reported that ATO had inhibitory effects on renal tubular cell injury. In human subjects Nakamura and co-workers (2006) presented data suggesting that pitavastatin ameliorated tubulointerstitial damage in CKD patients. That effect was independent of the lipid-lowering effect (Nakamura et al., 2006).

The pleiotropic effects of statins have important clinical implications, independent of their lipid-lowering effects (Fathi et al., 2004; Tonelli et al., 2004; Epstein and Campese, 2005; Nissen et al., 2005; Ridker et al., 2005; Goicoechea et al., 2006; Panichi et al., 2006; Renke et al., 2010). In our previous pilot study we confirmed that ATO therapy attenuated oxidative stress in patients with CKD (Renke et al., 2010). They are at an increased risk 
for CVD, and recent reviews suggested that inflammation and oxidative stress could be the primary mediators explaining the burden of CVD in CKD patients (Arici \& Walls, 2001). Moreover, inflammation plays a central role in the progression of CKD (Tonelli et al., 2005; Zoja et al., 2006). Our study used hsCRP, a protein found in the blood, as a marker of inflammation. Interestingly, patients with elevated basal levels of CRP are at an increased risk of diabetes, hypertension and cardiovascular disease (Pradhan et al., 2001; Dehghan et al., 2007). In our study this parameter had a tendency to decrease with ATO treatment, but the result was not statistically significant $(P=0.47)$. The fact that most of the patients had serum hsCRP levels in the normal range at the beginning of the study is probably the main reason why our results are different from those of some other authors (Chang et al., 2002; Ichihara et al., 2002; Vernaglione et al., 2004). Our study confirms the findings of others (Newman et al., 2006; Shurraw \& Tonelli 2006; Newman et al., 2008) that ATO therapy is well tolerated by CKD patients. Adverse effects were not reported during the study period. It is unlikely that confounding factors might have influenced the outcome of the present study. The treatment periods did not differ with respect to blood pressure, patients 'sodium and protein intake as well as renal function. We believe that the nephroprotective properties of ATO need to be addressed further in future controlled long term studies.

A potential limitation of the study is the relatively small sample size, although it was sufficiently powered to detect a significant difference equal to the S.D. value between treatment periods. A further limitation would be the fact that the participants were selected on the basis of their stability. The 24-h urine collections used to assess proteinuria may be associated with significant collection errors, largely because of improper timing and missed samples, leading to over- and under-collection. In addition, one should realize that the potential benefits for tubules and interstitium were extrapolated from presumptive early surrogates. Such evidence should be confirmed by histological examination.

In conclusion, the study results suggest that treatment with ATO (40 mg/day) for 12 weeks in nondialysis patients with CKD induced, in addition to its lipid-lowering effect, a significant decrease in biomarkers of tubular injury and damage without change in proteinuria. The treatment was safe and well tolerated by patients.

\section{Acknowledgements}

The study was supported by grant from the Committee for Scientific Research through the Medical University of Gdansk (ST-4 and W-80). The authors thank Pfizer Polska and Adamed for providing drugs. The drug providers and sponsors had no involvement in the study design, patient recruitment, analysis, interpretation of data, writing of the report, or the decision to submit the report for publication.

\section{REFERENCES}

"Kidney Disease Outcomes Quality Initiative (K/DOQI) Group" (Corporate Author) (2003). K/DOQI clinical practice guidelines for management of dyslipidemias in patients with kidney disease. Am J Kidney Dis 41 (4 Suppl 3): I-IV, S1-S91.

Arici M, Walls J (2001) End-stage renal disease atherosclerosis and cardiovascular mortality: is C-reactive protein the missing link? Kidney Int 59: 407-14.
Banach M, Mikhailidis DP, Kjeldsen SE, Rysz J (2009) Time for new indications for statins? Med Sci Monit 15: MS1-MS5.

Bazzi C, Petrini C, Rizza V, Arrigo G, Napodano P, Paparella M, D'Amico G (2002) Urinary $N$-acetyl- $\beta$-glucosaminidase excretion is a marker of tubular cell dysfunction and a predictor of outcome in primary glomerulonephritis. Nephrol Dial Transplant 17: 1890-1896.

Bianchi S, Bigazzi R, Caiazza A, Campese VM (2003) A controlled prospective study of the effects of atorvastatin on proteinuria and progression of kidney disease. Am J Kidney Dis 41: 565-70.

Chan PC, Robinson JD, Yeung WC, Cheng IK, Yeung HW, Tsang MT (1992) Lovastatin in glomerulonephritis patients with hyperlipidaemia and heavy proteinuria. Nephrol Dial Transplant 7: 93-99.

Chang JW, Yang WS, Min WK, Lee SK, Park JS, Kim SB (2002) Effects of simvastatin on high-sensitivity C-reactive protein and serum albumin in hemodialysis patients. Am J Kidney Dis 39: 1213-1217.

Cockcroft DW, Gault MH (1976) Prediction of creatinine clearance from serum creatinine. Nephron 16: 31-41.

Dehghan A, Kardys I, de Maat MP, Uitterlinden AG, Sijbrands EJ, Bootsma AH, Stijnen T, Hofman A, Schram MT, Witteman JC (2007) Genetic variation C-reactive protein levels and incidence of diabetes. Diabetes 56: 872-878.

Deslypere JP, Delanghe J, Vermeulen A (1990) Proteinuria as complication of simvastatin treatment. Lancet 336: 1453.

Epstein MV, Campese M (2005) Pleiotropic effects of 3-hydroxy-3methylglutaryl coenzyme a reductase inhibitors on renal function. Am J Kidney Dis 45: 2-14.

Fathi R, Isbel N, Short L, Haluska B, Johnson D, Marwick TH (2004) The effect of long-term aggressive lipid lowering on ischemic and atherosclerotic burden in patients with chronic kidney disease. Am J Kidney Dis 43: 45-52.

Fried LF, Orchard TJ, Kasiske BL (2001) Effect of lipid reduction on the progression of renal disease: a meta-analysis. Kidney Int 59: 260-269.

Fuiano G, Esposito C, Sepe V, Colucci G, Bovino M, Rosa M, Balletta M, Bellinghieri G, Conte G, Cianciaruso B, Dal Canton A (1996) Effects of hypercholesterolemia of renal hemodynamics: study in patients with nephrotic syndrome. Nephron 73: 430-435.

Goicoechea M, de Vinuesa SG, Lahera V, Cachofeiro V, GomezCampdera F, Vega A, Abad S, Luno J (2006) Effects of atorvastatin on inflammatory and fibrinolytic parameters in patients with chronic kidney disease. J Am Soc Nephrol 17 (12 Suppl 3): S231-S235.

Guijarro CW, Keane F (1993) Lipid abnormalities and changes in plasma proteins in glomerular diseases and chronic renal failure. Curr Opin Nephrol Hypertens 2: 372-379.

Holdt-Lehmann B, Lehmann A, Korten G, Nagel H, Nizze H, Schuff-Werner P (2000) Diagnostic value of urinary alanine aminopeptidase and $N$-acetyl- $\beta$-D-glucosaminidase in comparison to $\alpha_{1}$-microglobulin as a marker in evaluating tubular dysfunction in glomerulonephritis patients. Clin Chim Acta 297: 93-102.

Ichihara A, Hayashi M, Ryuzaki M, Handa M, Furukawa T, Saruta T (2002) Fluvastatin prevents development of arterial stiffness in haemodialysis patients with type 2 diabetes mellitus. Nephrol Dial Transplant 17: 1513-1517.

Keane WF, Kasiske BL, O’Donnell MP (1988) Hyperlipidemia and the progression of renal disease. Am J Clin Nutr 47: 157-160.

Maroni BJ, Steinman TI, Mitch WE (1985) A method for estimating nitrogen intake of patients with chronic renal failure. Kidney Int 27: 58-65.

Maruhn D (1976) Rapid calorimetric assay of $\beta$-galactosidase and $N$-acetyl- $\beta$-D-glucosaminidase in human urine. Clin Chim Acta 73: 453-461.

McKenney JM, Davidson MH, Jacobson TA, Guyton JR (2006) Final conclusions and recommendations of the National Lipid Association Statin Safety Assessment Task Force. Am J Cardiol 97: 89C94C.

Nakamura T, Sugaya T, Kawagoe Y, Suzuki T, Inoue T, Node K (2006) Effect of pitavastatin on urinary liver-type fatty-acid-binding protein in patients with nondiabetic mild chronic kidney disease. Am J Nephrol 26: 82-86.

Newman C, Tsai J, Szarek M, Luo D, Gibson E (2006) Comparative safety of atorvastatin $80 \mathrm{mg}$ versus $10 \mathrm{mg}$ derived from analysis of 49 completed trials in 14236 patients. Am J Cardiol 97: 61-67.

Newman CB, Szarek M, Colhoun HM, Betteridge DJ, Durrington PN, Hitman GA, Neil HA, Demicco DA, Auster S, Fuller JH (2008) The safety and tolerability of atorvastatin $10 \mathrm{mg}$ in the Collaborative Atorvastatin Diabetes Study (CARDS) Diab Vasc Dis Res 5: $177-183$

Nissen SE, Tuzcu EM, Schoenhagen P, Crowe T, Sasiela WJ, Tsai J, Orazem J, Magorien RD, O'Shaughnessy C, Ganz P (2005) Statin therapy LDL cholesterol C-reactive protein and coronary artery disease. N Engl J Med 352: 29-38.

Panichi V, Paoletti S, Mantuano E, Manca-Rizza G, Filippi C, Santi S, Taccola D, Donadio C, Tramonti G, Innocenti M, Casto G, Consani C, Sbragia G, Franzoni F, Galetta F, Panicucci E, Barsotti G (2006) In vivo and in vitro effects of simvastatin on inflammatory markers in pre-dialysis patients. Nephrol Dial Transplant 21: 337-344. 
Pradhan AD, Manson JE, Rifai N, Buring JE, Ridker PM (2001) Creactive protein interleukin 6 and risk of developing type 2 diabetes mellitus. Jama 286: 327-334.

Renke M, Knap N, Tylicki L, Rutkowski P, Neuwelt A, Larczynski W, Wozniak M, Rutkowski B (2010a) Atorvastatin attenuates oxidative stress in patients with chronic kidney disease. Med Sci Monit 16: LE3-LE3.

Renke M, Tylicki L, Rutkowski P, Knap N, Zietkiewicz M, Neuwelt A, Aleksandrowicz E, Lysiak-Szydlowska W, Wozniak M, Rutkowski B (2010b) Effect of pentoxifylline on proteinuria markers of tubular injury and oxidative stress in non-diabetic patients with chronic kidney disease - placebo controlled randomized cross-over study. Acta Biochim Pol 57: 119-123.

Ridker PM, Cannon CP, Morrow D, Rifai N, Rose LM, McCabe CH, Pfeffer MA, Braunwald E (2005) C-reactive protein levels and outcomes after statin therapy. N Engl J Med 352: 20-28.

Rutkowski B, Szolkiewicz M, Korczynska J, Sucajtys E, Stelmanska E, Nieweglowski T, Swierczynski J (2003) The role of lipogenesis in the development of uremic hyperlipidemia. Am J Kidney Dis 41 (3 Suppl 1): S84-S88.

Samuelsson O, Mulec H, Knight-Gibson C, Attman PO, Kron B, Larsson R, Weiss L, Wedel H, Alaupovic P (1997) Lipoprotein abnormalities are associated with increased rate of progression of human chronic renal insufficiency. Nephrol Dial Transplant 12: 1908-1915.

Sandhu S, Wiebe N, Fried LF, Tonelli M (2006) Statins for improving renal outcomes: a meta-analysis. J Am Soc Nephrol 17: 2006-2016.

Shurraw SM, Tonelli M (2006) Statins for treatment of dyslipidemia in chronic kidney disease. Perit Dial Int 26: 523-539.
Strippoli GF, Navaneethan SD, Johnson DW, Perkovic V, Pellegrini F, Nicolucci A, Craig JC (2008) Effects of statins in patients with chronic kidney disease: meta-analysis and meta-regression of randomised controlled trials. Bmi 336: 645-651.

Tonelli M (2006) The effect of statins on preservation of kidney function in patients with coronary artery disease. Curr Opin Cardiol 21: 608-612.

Tonelli M, Isles C, Curhan GC, Tonkin A, Pfeffer MA, Shepherd J, Sacks FM, Furberg C, Cobbe SM, Simes J, Craven T, West M (2004) Effect of pravastatin on cardiovascular events in people with chronic kidney disease. Circulation 110: 1557-1563.

Tonelli M, Sacks F, Pfeffer M, Jhangri GS, Curhan G (2005) Biomarkers of inflammation and progression of chronic kidney disease. Kidney Int 68: 237-245.

Tsujihata M, Momohara C, Yoshioka I, Tsujimura A, Nonomura N, Okuyama A (2008) Atorvastatin inhibits renal crystal retention in a rat stone forming model. J Urol 180: 2212-2217.

Tylicki L, Rutkowski B, Horl WH (2003) Antioxidants: a possible role in kidney protection. Kidney Blood Press Res 26: 303-314.

Verhulst A, D'Haese PC, De Broe ME (2004) Inhibitors of HMG$\mathrm{CoA}$ reductase reduce receptor-mediated endocytosis in human kidney proximal tubular cells. J Am Soc Nephrol 15: 2249-2257.

Vernaglione L, Cristofano C, Muscogiuri P, Chimienti S (2004) Does atorvastatin influence serum C-reactive protein levels in patients on long-term hemodialysis? Am J Kidney Dis 43: 471-478.

Zoja C, Abbate M, Remuzzi G (2006) Progression of chronic kidney disease: insights from animal models. Curr Opin Nephrol Hypertens 15: $250-257$. 